\title{
Offgassing Characterization of the Columbus Laboratory Module
}

\author{
Riccardo Rampini, Cesare Lobascio \\ Alenia Spazio S.p.A. \\ Jay L. Perry \\ NASA Marshall Space Flight Center \\ Stephan Hinderer \\ EADS Space Transportation GmbH
}

Copyright $@ 2005$ SAE International

\begin{abstract}
Trace gaseous contamination in the cabin environment is a major concern for manned spacecraft, especially those designed for long duration missions, such as the International Space Station (ISS).

During the design phase, predicting the European-built Columbus laboratory module's contribution to the ISS'S overall trace contaminant load relied on "trace gas budgeting" based on material level and assembled article tests data. In support of the Qualification Review, a final offgassing test has been performed on the complete Columbus module to gain cumulative system offgassing data.
\end{abstract}

Comparison between the results of the predicted offgassing load based on the budgeted material/assembled article-level offgassing rates and the module-level offgassing test is presented. The Columbus module offgassing test results are also compared to results from similar tests conducted for Node 1, U.S. Laboratory, and Airlock modules.

\section{INTRODUCTION}

Trace gaseous contamination in the cabin environment is a major concern for manned spacecraft, especially those designed for long duration missions, such as the ISS. Potential health risks to the crew can arise if the concentrations of trace atmospheric components are not properly controlled. A contaminated environment can also adversely affect sensitive payloads and equipment accommodated in the spacecraft.

For these reasons, design requirements for ISS modules place limits on internal airborne contamination by defining spacecraft maximum allowable concentrations (SMACs) for trace atmospheric components. Controls rely on a combination of passive and active methods. Passive methods include carefully selecting materials of construction and manufacturing processes as well as regulating in-flight operations performed by the crew. Active methods include maintaining adequate ventilation rates and deploying air quality control equipment to continually remove contaminants from the cabin atmosphere. Monitoring systems ensure that the passive and active control methods are working. The Europeanbuilt Columbus laboratory module (Figure 1) employs primarily passive controls and relies upon ventilation with and active air quality control equipment located in interfacing modules elements to continually remove contaminants produced by equipment offgassing.

During the design phase, predicting the Columbus module's contribution to the ISS'S overall trace contaminant load relied on "trace gas budgeting" based on material level and assembled article tests data. Cases for both on-orbit and isolated conditions were analyzed. In support of the Qualification Review, a final offgassing test has been performed on the complete Columbus module to gain cumulative system offgassing data. Test results have been utilized for a final offgassing evaluation, where predictions for the same cases, onorbit and isolated, have been formulated. The test has been conducted in active mode, representative of the onorbit module condition, and the offgassing rate results have been conservatively extended also to the passive mode, representative of isolated module conditions.

Comparison between the results of the predicted offgassing load based on the budgeted material/assembled article-level offgassing rates and the module-level offgassing test is presented. The Columbus module offgassing test results are also compared to results from similar tests conducted for Node 1, U.S. Laboratory, and Airlock modules. 


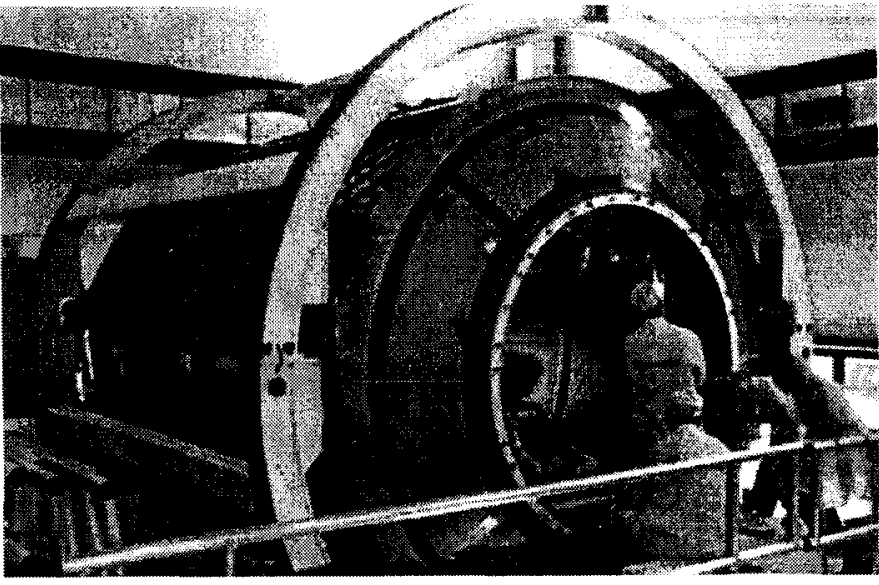

Figure 1 - The European-built Columbus laboratory module

\section{APPLICABLE SMACS}

For the Columbus module, as for the other ISS modules, a set of contractually applicable SMACs has been established. The Columbus SMACs list, coming from the Columbus System Requirements Document (CSRD) [1], reports the SMACs for 24 airborne contaminants, for 5 different potential exposure periods, as showed in Table 1.

\begin{tabular}{|c|c|c|c|c|c|c|}
\hline & \multicolumn{5}{|c|}{ Polential Exposure Period } \\
\hline & & $1 \mathrm{~h}$ & $24 h$ & $7 d$ & $30 d$ & $180 \mathrm{~d}$ \\
\hline Acetaldehyde & $\mathrm{mg} / \mathrm{m}^{3}$ & 20 & 10 & 4 & 4 & 4 \\
\hline Acrolein & $\mathrm{mg} / \mathrm{m}^{3}$ & 0.2 & 0.08 & 0.03 & 0.03 & 0.03 \\
\hline Ammonia & $\mathrm{mg} / \mathrm{m}^{3}$ & 20 & 14 & 7 & 7 & 7 \\
\hline Carbon dioxide & $\mathrm{mmHg}$ & 10 & 10 & 5.3 & 5.3 & 5.3 \\
\hline Carbon monoxide & $\mathrm{mg} / \mathrm{m}^{3}$ & 60 & 20 & 10 & 10 & 10 \\
\hline 1,2-Dichloroethane & $\mathrm{mg} / \mathrm{m}^{3}$ & 2 & 2 & 2 & 2 & 1 \\
\hline 2-Ethoxyethanol & $\mathrm{mg} / \mathrm{m}^{3}$ & 40 & 40 & 3 & 2 & 0.3 \\
\hline Formaldehyde & $\mathrm{mg} / \mathrm{m}^{3}$ & 0.5 & 0.12 & 0.05 & 0.05 & 0.05 \\
\hline Freon 113 & $\mathrm{mg} / \mathrm{m}^{3}$ & 400 & 400 & 400 & 400 & 400 \\
\hline Hydrazine & $\mathrm{mg} / \mathrm{m}^{3}$ & 5 & 0.4 & 0.05 & 0.03 & 0.005 \\
\hline Hydrogen & $\mathrm{mg} / \mathrm{m}^{3}$ & 340 & 340 & 340 & 340 & 340 \\
\hline Indole & $\mathrm{mg} / \mathrm{m}^{3}$ & 5 & 1.5 & 0.25 & 0.25 & 0.25 \\
\hline Mercury & $\mathrm{mg} / \mathrm{m}^{3}$ & 0.1 & 0.02 & 0.01 & 0.01 & 0.01 \\
\hline Methane & $\mathrm{mg} / \mathrm{m}^{3}$ & 3800 & 3800 & 3800 & 3800 & 3800 \\
\hline Methanol & $\mathrm{mg} / \mathrm{m}^{3}$ & 40 & 13 & 9 & 9 & 9 \\
\hline Methyl ethy ketone & $\mathrm{mg} / \mathrm{m}^{3}$ & 150 & 150 & 30 & 30 & 30 \\
\hline Methyl hydrazine & $\mathrm{mg} / \mathrm{m}^{3}$ & 0.004 & 0.004 & 0.004 & 0.004 & 0.004 \\
\hline Dichloromethane & $\mathrm{mg} / \mathrm{m}^{3}$ & 350 & 120 & 50 & 20 & 10 \\
\hline Octamethyttrisilaxane & $\mathrm{mg} / \mathrm{m}^{3}$ & 4000 & 2000 & 1000 & 200 & 40 \\
\hline 2-Propanol & $\mathrm{mg} / \mathrm{m}^{3}$ & 1000 & 240 & 150 & 150 & 150 \\
\hline Toluene & $\mathrm{mg} / \mathrm{m}^{3}$ & 60 & 60 & 60 & 60 & 60 \\
\hline Trichloroethylene & $\mathrm{mg} / \mathrm{m}^{3}$ & 270 & 60 & 50 & 20 & 10 \\
\hline Trimethyssilanol & $\mathrm{mg} / \mathrm{m}^{3}$ & 600 & 70 & 40 & 40 & 40 \\
\hline Xylene & $\mathrm{mg} / \mathrm{m}^{3}$ & 430 & 430 & 220 & 220 & 220 \\
\hline
\end{tabular}

Table 1 - Columbus SMACs

\section{DESIGN PHASE PREDICTIONS}

During the design phase, predicting the Columbus module's contribution to the ISS's overall trace contaminant load relied on "trace gas budgeting" based on material level, assembled article tests data and metabolic generation. For the purpose, dedicated spreadsheets and databases using Microsoft Excel ${ }^{\odot}$ and Access $^{\ominus}$ have been developed.

MATERIAL GENERATION RATES - Evaluation of trace gas concentrations has been performed by "budgeting" all the Columbus materials, their masses and off-gassing rates.

Off-gassing information have been collected from all Columbus system, subsystem and equipment level responsible parties, exception made for ISS common items. The reason for this is that ISS does not use offgassing summations at equipment level anymore, thus materials lists are available only for a limited number of common items. Their contribution, in terms of offgassing generation rates, has been obtained by multiplying the historical offgassing generation rates from previous manned missions by their non-structural hardware mass.

For researching Columbus materials, checking provided data and supplementing insufficient information, extensive research has been performed on:

- NASA MAPTIS on-line database

- ESA RD: 02, Toxicity and Flammability Data for Spacecraft Materials

- Columbus Declared Materials, Mechanical Parts and Processes Lists

Off-gassing rates have been conservatively assumed constant over time, since decay laws are generally not available for specific materials.

CREW GENERATION RATES - Crew metabolic generation rates, necessary for the analysis of Columbus nominal conditions, have been derived from research on literature references such as the draft version of ESAPSS-03-401, [2], SAE paper 891513 [3], both tracing back to H-EV-1-12-CNES, Physiological Environment Human Factors Limitations [4]. For $\mathrm{CO}_{2}$ metabolic rates, International Space Station Alpha System Specification [5], Table XXIX data have been used.

ANALYSIS CASES - The trace gas analysis considered that two different Columbus conditions are foreseen:

- isolated, with Columbus working without Inter Module Ventilation (IMV) air exchange

- nominal, the Columbus working with IMV air exchange

SMAC VALUES - Since material test data are not limited to the 24 gases contained into the Columbus SMAC list, analytical predictions compared resulting concentrations to a more extended gas set. The contractually applicable CSRD SMACs in Table 1 have been considered for requirement verification. More precisely, we considered the 180 days SMACs for the nominal analysis and the 1 hour SMACs for the isolated analysis.

For additional comparisons, we considered:

- For other detected trace gases, SMACs from the MAPTIS database, typically 7 days SMACs.

- Where only a Total Organics (TO) value was available from test data, a SMAC of $0.1 \mathrm{mg} / \mathrm{m}^{3}$, conservative as a mean SMAC of a hypothetical 
$\because \begin{aligned} & \text { organic gas mixture (see also MAPTIS default } \\ & \text { value). }\end{aligned}$

- For unidentified traces of every kind, a SMAC of 0.1 $\mathrm{mg} / \mathrm{m}^{3}$, as used inside MAPTIS.

DESIGN DATA - Design data of interest for the analysis were:

- IMV air flow rate $-229 \mathrm{~m}^{3} / \mathrm{h}$

- Columbus volume - $64 \mathrm{~m}^{3}$

- Columbus isolation time - elapsing between hatch close-out on-ground (Astrium-Bremen clean room) and hatch reopening on-station, currently estimated as 180 days

RESULTS - Results were directly obtained from the generated database, in terms of concentrations. Trace gas contamination levels in the IMV supply air (ISS to Columbus) or, as equivalent, the removal rates at the Columbus IMV interface are unknown. Therefore we evaluated the "Columbus contribution" to Columbus concentration levels: actual Columbus levels will be the sum of the Columbus contribution plus the IMV contribution. To assess performances of the ISS trace gas removal system, the ISS performs an overall analysis.

Here below the main results relevant to the two analyzed cases are reported and compared to the applicable SMACs.

For easier interpretation of results, the concentration to SMAC ratios are also reported as well as the Time to SMAC for the isolated conditions.

\begin{tabular}{|l|c|c|c|c|}
\hline Trace gas & $\begin{array}{c}\text { Generation } \\
\text { rate } \\
{[\mathrm{mgh}]}\end{array}$ & $\begin{array}{c}\text { APM contribution } \\
\text { to concentration } \\
{\left[\mathrm{mg}^{3} / \mathrm{m}^{3}\right]}\end{array}$ & $\begin{array}{c}\text { SMACs }(180 \mathrm{~d}) \\
{\left[\mathrm{mg} / \mathrm{m}^{3}\right]}\end{array}$ & $\begin{array}{c}\text { Concentration to } \\
\text { SMAC (180 d) ratio } \\
{[-]}\end{array}$ \\
\hline Indole & 3.1 & $1.36 \mathrm{E}-02$ & 0.25 & $5.46 \mathrm{E}-02$ \\
\hline Carton dioxide & 127000.0 & $5.56 \mathrm{E}+02$ & 13000 & $4.27 \mathrm{E}-02$ \\
\hline Ammonia & 59.4 & $2.59 \mathrm{E}-01$ & 7 & $3.70 \mathrm{E}-02$ \\
\hline Formaldehyde & 0.3 & $1.30 \mathrm{E}-03$ & 0.05 & $2.60 \mathrm{E}-02$ \\
\hline 2-Propanol & 227.0 & $9.90 \mathrm{E}-01$ & 150 & $6.60 \mathrm{E}-03$ \\
\hline Carbon monoxide & 10.2 & $4.46 \mathrm{E}-02$ & 10 & $4.46 \mathrm{E}-03$ \\
\hline Methanol & 3.0 & $1.32 \mathrm{E}-02$ & 9 & $1.47 \mathrm{E}-03$ \\
\hline Trimethylsilanol & 5.9 & $2.59 \mathrm{E}-02$ & 40 & $6.47 \mathrm{E}-04$ \\
\hline Acrolein & 0.0 & $1.17 \mathrm{E}-05$ & 0.03 & $3.89 \mathrm{E}-04$ \\
\hline Acetakdehyde & 0.3 & $1.42 \mathrm{E}-03$ & 4 & $3.55 \mathrm{E}-04$ \\
\hline Toluene & 4.3 & $1.89 \mathrm{E}-02$ & 60 & $3.16 \mathrm{E}-04$ \\
\hline Trichloroethylene & 0.5 & $2.19 \mathrm{E}-03$ & 10 & $2.19 \mathrm{E}-04$ \\
\hline Methyl ethyl ketone & 1.3 & $5.59 \mathrm{E}-03$ & 30 & $1.86 \mathrm{E}-04$ \\
\hline 2-Ethoxyethanol & 0.0 & $4.66 \mathrm{E}-05$ & 0.3 & $1.55 \mathrm{E}-04$ \\
\hline Dichloromethane & 0.2 & $1.02 \mathrm{E}-03$ & 10 & $1.02 \mathrm{E}-04$ \\
\hline Methane & 76.4 & $3.34 \mathrm{E}-01$ & 3800 & $8.76 \mathrm{E}-05$ \\
\hline Hydrogen & 6.3 & $2.73 \mathrm{E}-02$ & 340 & $8.03 \mathrm{E}-05$ \\
\hline Freon 113 & 2.7 & $1.17 \mathrm{E}-02$ & 400 & $2.93 \mathrm{E}-05$ \\
\hline Xylene (sum) & 0.4 & $1.59 \mathrm{E}-03$ & 220 & $7.23 \mathrm{E}-06$ \\
\hline 1,2-0ichloroethane & 0.0 & $6.00 \mathrm{E}-06$ & 1 & $6.00 \mathrm{E}-06$ \\
\hline Octamethyltrisiloxane & 0.0 & $1.82 \mathrm{E}-05$ & 40 & $4.56 \mathrm{E}-07$ \\
\hline Hydrazine & 0.0 & $0.00 \mathrm{E}+00$ & 0.005 & $0.00 \mathrm{E}+00$ \\
\hline Mercury & 0.0 & $0.00 \mathrm{E}+00$ & 0.01 & $0.00 \mathrm{E}+00$ \\
\hline Methylhydrazine & 0.0 & $0.00 \mathrm{E}+00$ & 0.004 & $0.00 \mathrm{E}+00$ \\
\hline
\end{tabular}

Table 2 - On station nominal conditions, main analysis results

For the on station nominal conditions the calculated concentrations have been compared with relevant 180 days CSRD SMACs, i.e. the ones to be considered for long term exposure. On the other hand, for isolated conditions, the calculated concentrations have been compared with relevant 1 hour CSRD SMACs, i.e. the ones to be considered for short term exposure. We supposed that the crew could be exposed to such levels for less than one hour, i.e. the 'relatively high concentrations' reached during the isolation phase will quickly decrease in the first hours due to air revitalization via IMV/hatch.

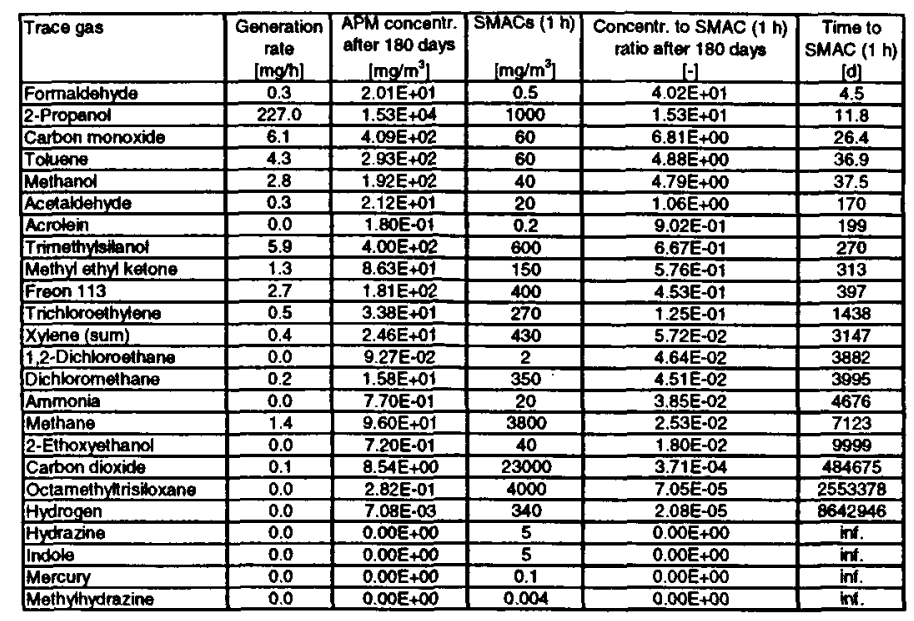

Table 3 - Isolated conditions, main analysis results

\section{FINAL OFFGASSING TEST}

In support of the Columbus Qualification Review, a final offgassing test has been performed on the complete Columbus module to gain cumulative system offgassing data. Test results have been utilized for a final offgassing evaluation, where predictions for on-orbit and isolated cases have been formulated. The test has been conducted in active mode, representative of the on-orbit module condition, and the offgassing rate results have been conservatively extended also to the passive mode, representative of isolated module conditions.

TEST ARTICLE CONFIGURATION - During the test the Columbus module has been operated in nominal active mode simulating realistic on-orbits processes besides payload operation, i.e. with Columbus internal equipment configured as much as possible in "flight conditions" but without any payload rack. This means in particular all subsystems activated: Electrical Power Distribution System (EPDS), Data Management System (DMS), Active Thermal Control System (ATCS), Environmental Control and Life Support System (ECLSS), Video and lllumination.

An offgassing test with Columbus in passive mode, representative of the isolated phase, will be performed, under ESANASA responsibility, with the module outfitted with the initial payload complement, to characterize the Columbus isolated atmosphere.

Columbus internal layout was as close as possible to the flight configuration. Devices not foreseen for flight, and not strictly necessary for test execution were not present. Only the Ground Operation Floor (Aluminum structure) was left inside Columbus for allowing access to the module interior. The impact of this discrepancy with 
respect to the test objectives is not significant because of the metallic material nature.

Every subsystem, in particular ECLSS, ATCS and Avionics, was fully integrated. In order to verify offgassing properties of all materials involved in the cabin hardware, every non-metallic internal equipment has been placed into the cabin if not already integrated. Concerning the DMS, the Columbus test configuration was not final. In particular additional Personal Computer Memory Card International Association (PCMCIA) cards were not present into the module during the test. Their contribution to offgassing has been considered by analysis on the basis of card level offgassing data.

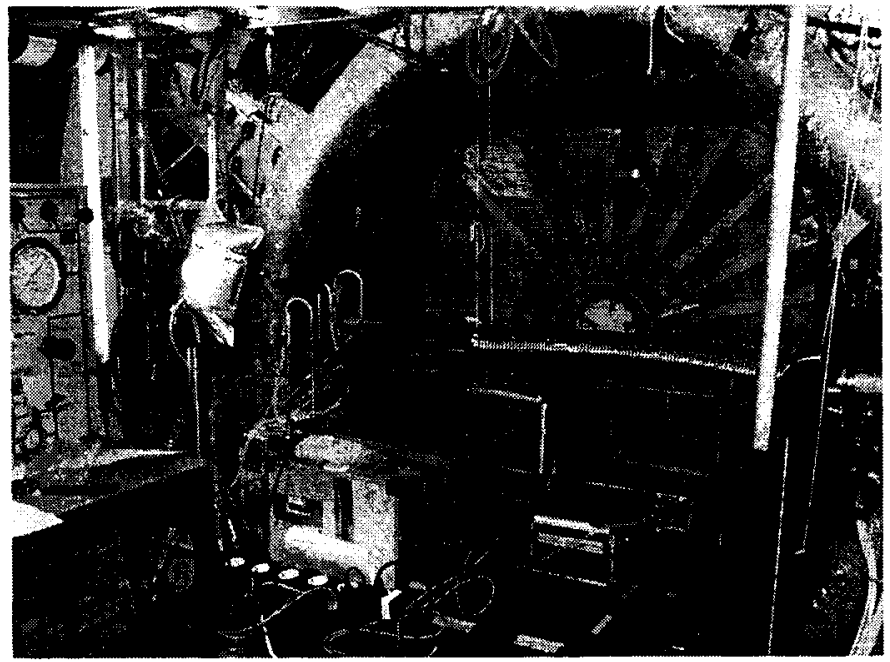

Figure 2-Columbus module during the offgassing test

In order to prevent air exchange with the cleanroom, the Module has been isolated from the external atmosphere, i.e. the Hatch has been closed, and the Starboard Cone Aft Panel (SAC) installed. The IMV loop was shortcircuited outside the module by means of a metallic jumper. The IMV jumper provided several sampling ports for the air sample acquisition.

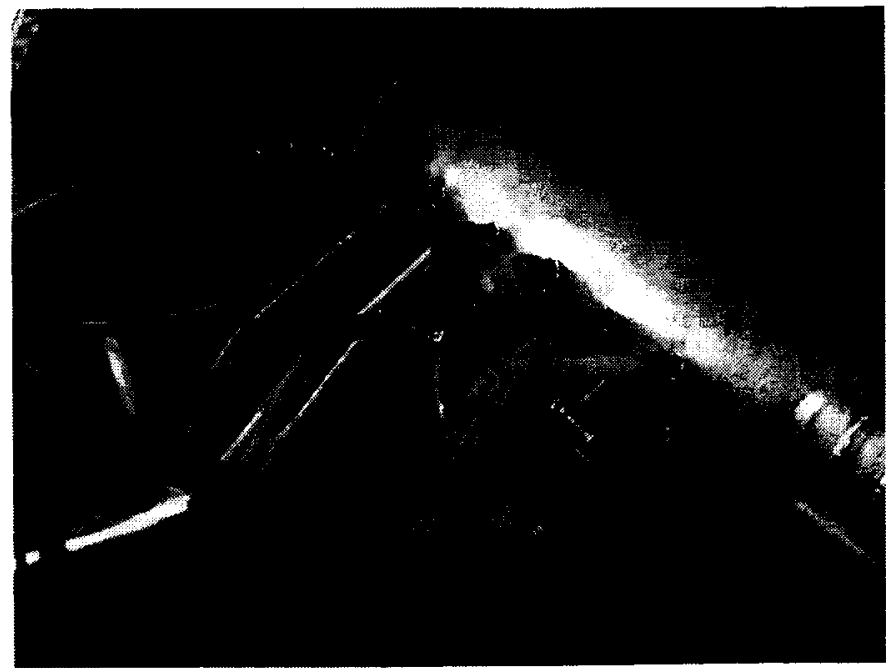

Figure 3 - IMV jumper with the sampling ports

STANDARD TEST AND LABORATORY EQUIPMENT The air samples has been collected by means of adsorption traps, Dinitrophenylhydrazine (DNPH). cartridges and gas sampling bags adapted to the contaminant analysis process. Depending on the gas to be detected, samples have then been analyzed by means of Gas Chromatography - Mass Spectrometry (GC-MS), High Performance Liquid Chromatography Diode Array Detection (HPLC-DAD) or Gas Chromatography - Flame Ionization Detector (GC-FID) techniques.

TEST SEQUENCE - The Columbus Offgassing Test has been executed into the integration and test hall, B41 at EADS ST premises in Bremen, during the Mission Simulation Test (MST), from the $2^{\text {nd }}$ to the $5^{\text {th }}$ of April 2004.

Internal cleaning with volatile solvents has been stopped four weeks before closure of the module, in order to avoid the entrapment of unwanted gaseous trace contaminants and to assure that the maximum evaporation of solvents has occurred. Moreover, during the first days of the Mission Simulation Test, the Columbus module was already operated in nominal mode with the hatch open and air exchange with the cleanroom. This period was considered as a purging of the module from those possible unwanted gaseous trace contaminants. The actual Offgassing Test started as the module was isolated from the cleanroom, i.e. with the hatch closure and the IMV short-circuiting.

The module has been kept isolated and powered for a total of approximately 74 hours. After two initial background sample set, representative of both clean room and Columbus trace contaminants levels, 6 additional sample sets were taken, totaling in all 8 sample sets. The background sampling has been performed:

- approximately 4 days before the test, inside the module, with the hatch open, and

- at the very beginning of the test, just after closure of the hatch

The first background sampling of the clean room environment, taken approximately 4 days before the beginning of the Offgassing Test, was intended not only to measure the background contamination but also to optimize the needed sampling volumes. The volume of each sample was tailored to the needed accuracy.

The detailed sampling sequence is reported in Table 4.

The Columbus module has been operated with a slight overpressure in order to avoid incoming air from the cleanroom. Therefore, after each sampling activity the module has been repressurized to recover the pressure decay due to the sampling itself. The module pressurization has been performed with a Nitrogen Pressure Supply Unit, utilizing class 4 nitrogen. The overpressure has been checked at least every 12 hours. 
For closure of the Columbus offgassing requirements, - just the gases defined in the CSRD SMAC table have been evaluated. Only for the first and the last acquisition, OGAS 010 and OGAS 080 samplings, a comprehensive analysis has been performed in order to detect all potential gases according to a "common" offgassing test. These two additional sets of results were for information only and they were not subject of evaluation for the closure of the Columbus offgassing requirements.

\begin{tabular}{|c|c|c|c|}
\hline $\begin{array}{l}\text { Procedure } \\
\text { Module }\end{array}$ & Date & Sampling Time & $\begin{array}{l}\text { Sampled } \\
\text { volume [U] }\end{array}$ \\
\hline \multirow{2}{*}{ OGAS 010} & \multirow{2}{*}{29.03 .04} & Start: 11.20 & \multirow{2}{*}{ (Hatch open) } \\
\hline & & End: 14.15 & \\
\hline \multirow{2}{*}{ OGAS 020} & \multirow{2}{*}{02.04 .04} & Stant: 19.55 & \multirow{2}{*}{301.4} \\
\hline & & End: 22.07 & \\
\hline \multirow{2}{*}{ OGAS 030} & \multirow{2}{*}{03.04 .04} & Start: 00.00 & \multirow{2}{*}{299.2} \\
\hline & & End: 01.49 & \\
\hline \multirow{2}{*}{ OGAS 040} & \multirow{2}{*}{03.04 .04} & Start: 08.05 & \multirow{2}{*}{254.2} \\
\hline & & End: 09.56 & \\
\hline \multirow{2}{*}{ OGAS 050} & \multirow{2}{*}{03.04 .04} & Start: 18.06 & \multirow{2}{*}{719.2} \\
\hline & & End: 20.58 & \\
\hline \multirow{2}{*}{ OGAS 060} & \multirow{2}{*}{04.04 .04} & Start: 18.04 & \multirow{2}{*}{742.2} \\
\hline & & End: 20.38 & \\
\hline OGAS 070 & 05.04 .04 & Start: 08.03 & 744.2 \\
\hline \multirow{2}{*}{ OGAS 080} & \multirow{2}{*}{05.04 .04} & $\begin{array}{l}\text { End: } 10.37 \\
\text { Stant: } 19.34\end{array}$ & \multirow{2}{*}{754.5} \\
\hline & & End: 21.55 & \\
\hline
\end{tabular}

Table 4 - Sampling sequence

TEST RESULTS AND FINAL OFFGASSING EVALUATION - For each gas defined in the CSRD SMAC table, chemical analysis results and the calculated concentrations, suitably scaled due to $\mathrm{N}_{2}$ introduction during repressurization phases of the Columbus module, were presented and their trends were plotted in a dedicated "Gas data sheet", similar to the one represented in Figure 4.

On the same data sheet, calculation dedicated to the final offgassing evaluation were reported.

Final evaluation cases - As for the design phase predictions two cases have been analyzed:

- Nominal case: Columbus on-station in ACTIVE mode and IMV operating - representative of the onorbit module condition

- Isolated case: Columbus isolated in PASSIVE mode and IMV not operating - representative of the storage module condition. Remark: The test has been conducted in active mode and the HW generation results have been conservatively extended also to the passive mode. This analytical evaluation shall be considered only as an indication of the offgassing concentrations behavior inside the module in case of isolation

Design data - Design data of interest for the final offgassing evaluation are the same as for the design phase predictions, exception made for the Columbus free volume that have been re-evaluated to be close to $72 \mathrm{~m}^{3}$.

Trends - Depending on the recorded trend during the test of each gas, different data treatment have been implemented. Four main "trend groups" have been found:
- Measured concentrations leveling off, asymptotic level not reached - the production rates have been conservatively calculated from the concentration values of the last period of the test, i.e. between $\sim 60$ (OGAS 070) and $\sim 72$ hours (OGAS 080). Gases part of this group are: Acetaldehyde (see Figure 4), Methyl ethyl ketone and Toluene.

- Measured concentrations leveling off, asymptotic level reached - the production rates is considered to be zero at the end of the test. Gases part of this group are: 2-Propanol, Trichloroethylene, Trimethylsilanol and Xylenes (see Figure 5).

- Measured concentrations fluctuating - a linear interpolation, by using the least squares method, has been adopted for the calculation of the production rates. Gases part of this group are: Formaldehyde, Carbon dioxide, 1,2-Dichloroethane, 2-Ethoxyethanol (see figure 6), Freon 113, Octamethyltrisiloxane and Methane.

- Non detectable concentrations - the production rates have been conservatively calculated assuming the concentration at the end of the test equal to the detection limit for the specific gas. Gases part of this group are: Acrolein (see Figure 7), Carbon monoxide, Ammonia, Methanol and Dichloromethane. As a remark, we do not consider Hydrogen, Mercury, Indole, Hydrazine and Methyl hydrazine as part of this group since their production is avoided by design and by the absence of metabolic generation during the test.

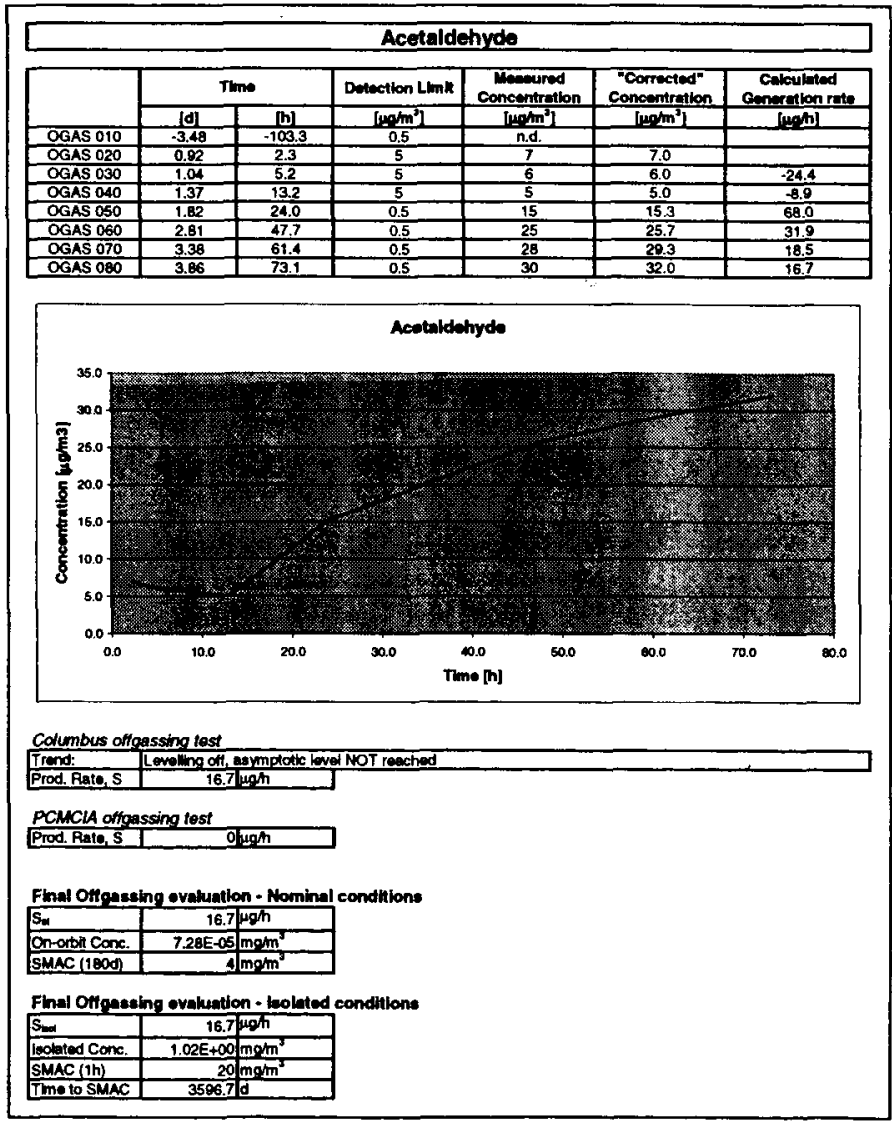

Figure 4 - Acetaldehyde data sheet 


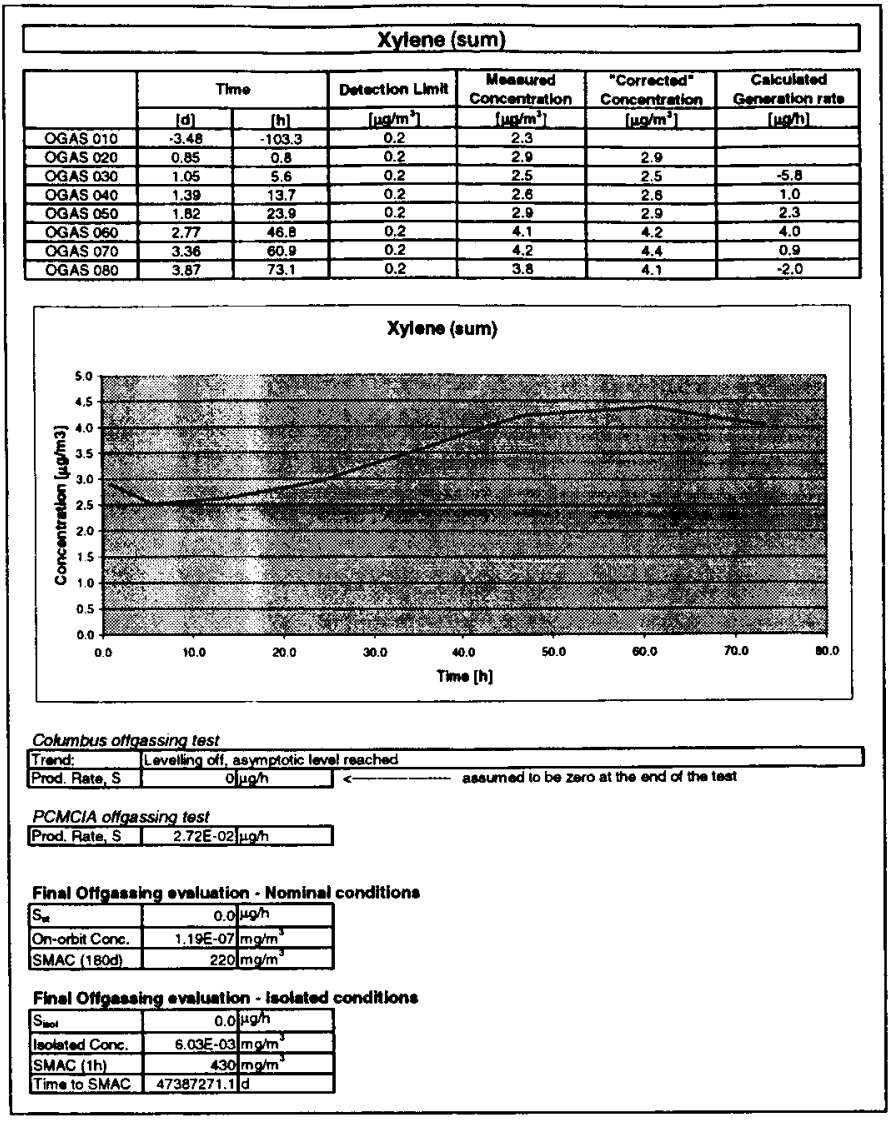

Figure 5 - Xylenes data sheet

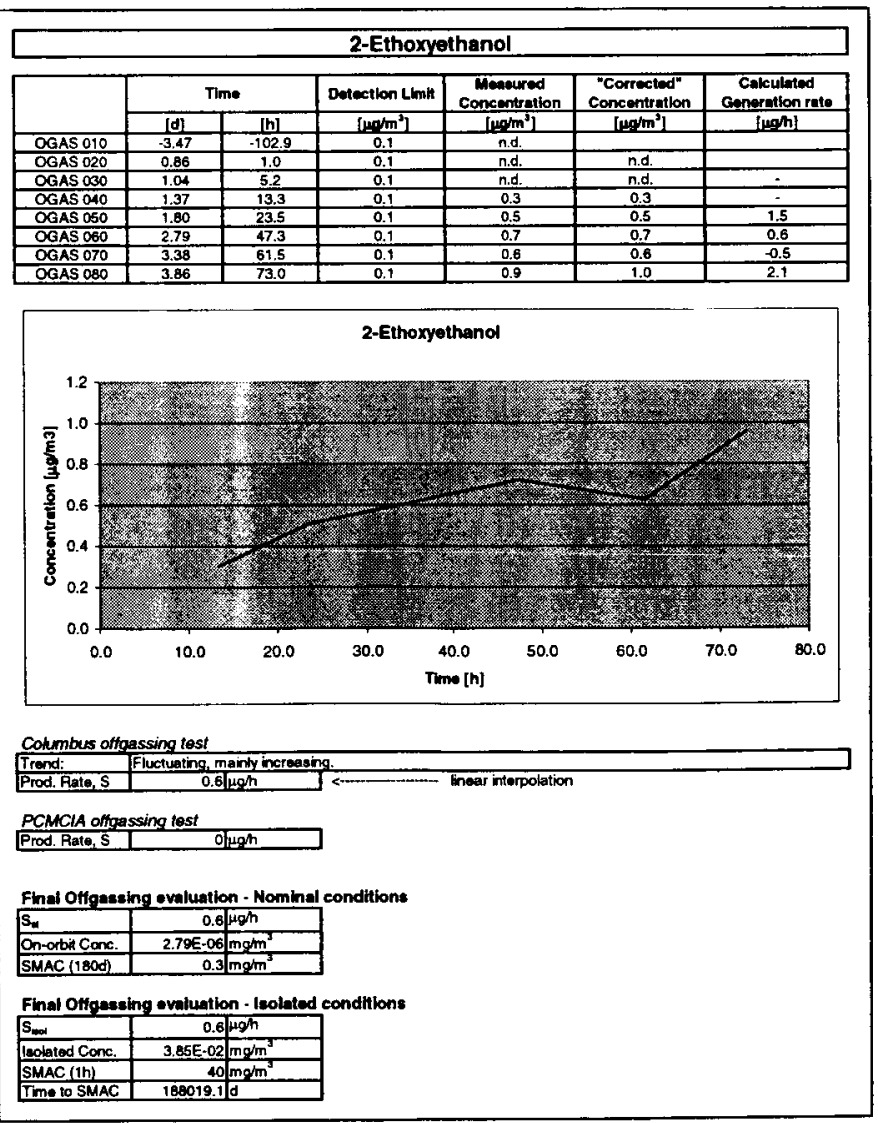

Figure 6 - 2-Ethoxyethanol data sheet
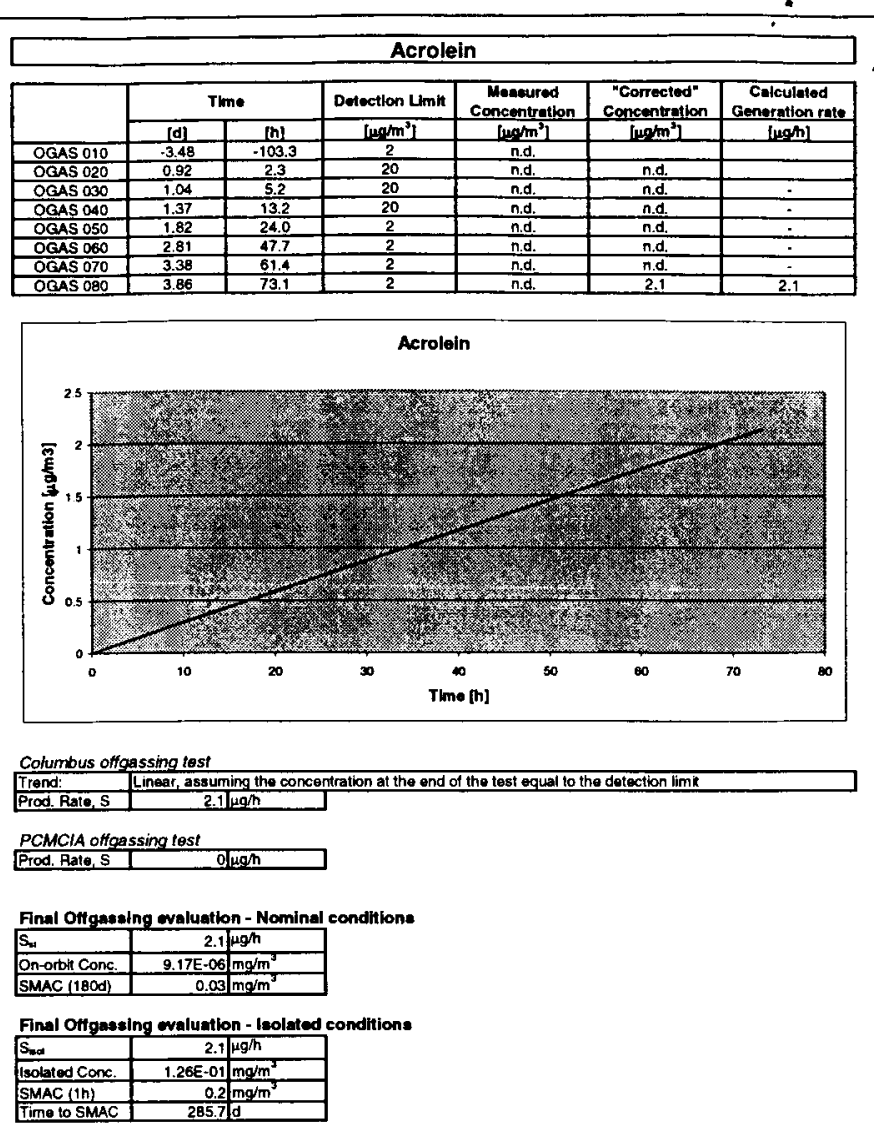

Figure 7 - Acrolein data sheet

Results summary - Results from the final offgassing test are summarized, in terms of concentrations, in Table 5 and 6 , respectively for the On station and the Isolated conditions. Also in this case, we calculated the "Columbus contribution" to Columbus concentration levels.

For easier interpretation of results, the concentration to SMAC ratios are also presented as well as the Time to SMAC for the isolated conditions.

\begin{tabular}{|l|c|c|c|c|}
\hline Trace gas & $\begin{array}{c}\text { Generation } \\
\text { rate } \\
{[\mathrm{mgh}]}\end{array}$ & $\begin{array}{c}\text { APM contribution } \\
\text { to concentration } \\
{\left[\mathrm{mg}^{3} \mathrm{~m}^{3}\right.}\end{array}$ & $\begin{array}{c}\text { SMACs (180 d) } \\
{\left[\mathrm{mg} / \mathrm{m}^{3}\right]}\end{array}$ & $\begin{array}{c}\text { Concentration to } \\
\text { SMAC (180 d) ratio } \\
{[]}\end{array}$ \\
\hline Acrolgin & 0.0021 & $9.17 \mathrm{E}-06$ & 0.03 & $3.06 \mathrm{E}-04$ \\
\hline Carbon monoxide & 0.27 & $1.18 \mathrm{E}-03$ & 10 & $1.18 \mathrm{E}-04$ \\
\hline Ammonia & 0.10 & $4.38 \mathrm{E}-04$ & 7 & $6.26 \mathrm{E}-05$ \\
\hline 1,2-Dichloroethane & 0.011 & $4.80 \mathrm{E}-05$ & 1 & $4.80 \mathrm{E}-05$ \\
\hline Methanol & 0.050 & $2.19 \mathrm{E}-04$ & 9 & $2.44 \mathrm{E}-05$ \\
\hline Acetaldehyde & 0.017 & $7.28 \mathrm{E}-05$ & 4 & $1.82 \mathrm{E}-05$ \\
\hline 2-Ethoxyethanol & 0.00064 & $2.79 \mathrm{E}-06$ & 0.3 & $9.29 \mathrm{E}-06$ \\
\hline Methylethyd ketone & 0.019 & $8.40 \mathrm{E}-05$ & 30 & $2.80 \mathrm{E}-06$ \\
\hline Toluene & 0.017 & $7.63 \mathrm{E}-05$ & 60 & $1.27 \mathrm{E}-06$ \\
\hline Dichloromethane & 0.0011 & $4.60 \mathrm{E}-06$ & 10 & $4.60 \mathrm{E}-07$ \\
\hline Methane & 0.16 & $6.96 \mathrm{E}-04$ & 3800 & $1.83 \mathrm{E}-07$ \\
\hline Octamethyltrisiloxane & 0.00046 & $2.01 \mathrm{E}-06$ & 40 & $5.02 \mathrm{E}-08$ \\
\hline 2-Propanol & 0.00038 & $1.68 \mathrm{E}-06$ & 150 & $1.12 \mathrm{E}-08$ \\
\hline Xylene (sum) & 0.000027 & $1.19 \mathrm{E}-07$ & 220 & $5.40 \mathrm{E}-10$ \\
\hline Fomaldehyde & 0 & $0.00 \mathrm{E}+00$ & 0.05 & $0.00 \mathrm{E}+00$ \\
\hline Carbon dioxide & 0 & $0.00 \mathrm{E}+00$ & 13000 & $0.00 \mathrm{E}+00$ \\
\hline Hydrogen & 0 & $0.00 \mathrm{E}+00$ & 340 & $0.00 \mathrm{E}+00$ \\
\hline Mercury & 0 & $0.00 \mathrm{E}+00$ & 0.01 & $0.00 \mathrm{E}+00$ \\
\hline Freon +13 & 0 & $0.00 \mathrm{E}+00$ & 400 & $0.00 \mathrm{E}+00$ \\
\hline Indole & 0 & $0.00 \mathrm{E}+00$ & 0.25 & $0.00 \mathrm{E}+00$ \\
\hline Trichloroethylene & 0 & $0.00 \mathrm{E}+00$ & 10 & $0.00 \mathrm{E}+00$ \\
\hline Trimethylsilanol & 0 & $0.00 \mathrm{E}+00$ & 40 & $0.00 \mathrm{E}+00$ \\
\hline Hydrazine & 0 & $0.00 \mathrm{E}+00$ & 0.005 & $0.00 \mathrm{E}+00$ \\
\hline Methylhydrazine & 0 & $0.00 \mathrm{E}+00$ & 0.004 & $0.00 \mathrm{E}+00$ \\
\hline
\end{tabular}

Table 5 - On station nominal conditions, from test results 


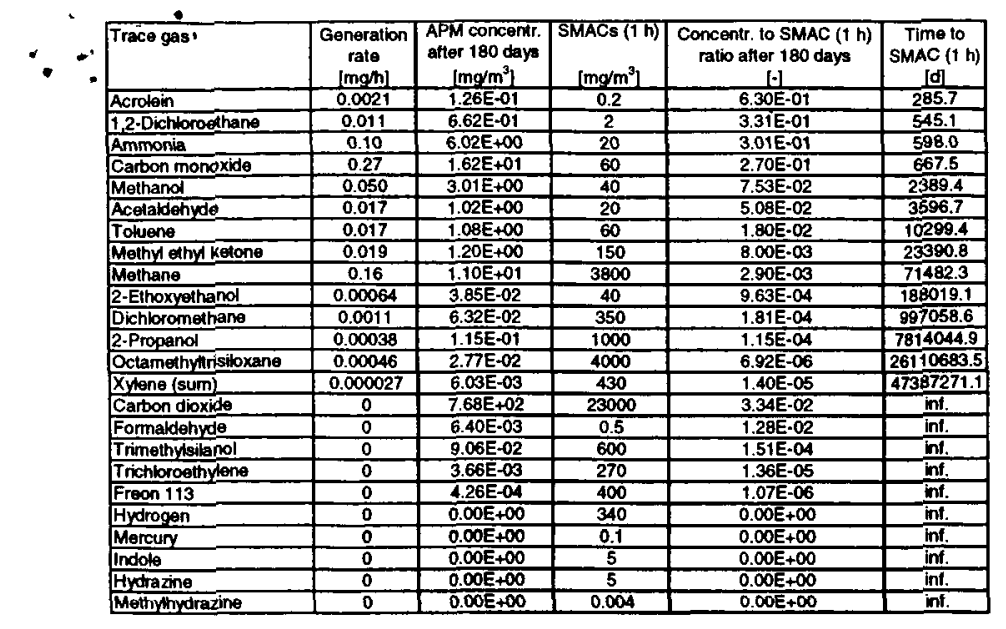

Table 6 - Isolated conditions, from test results

\section{COMPARISON BETWEEN ANALYTICAL PREDICTIONS AND TEST RESULTS}

An interesting exercise is to compare the analytical predictions by "trace gas budgeting" with the module level test results.

For this purpose the results of the design phase predictions have been treated to be congruent with the ones coming from the offgassing test:

- For the On station case - the load due to metabolic production, to the Portable Fire Extinguisher (PFEX), and to the Portable Breathing Apparatus (PBA), not present during the test, but taken into account in the design analysis, has been subtracted

- For the Isolated case - results coming from the design phase analysis have been suitably scaled in order to consider the new Columbus free volume of $72 \mathrm{~m}^{3}$ instead of $64 \mathrm{~m}^{3}$

This comparison is presented in Table 7 , for the On station conditions and Table $\mathbf{8}$, for the Isolated conditions.

From table 7 the following can be remarked:

- Five gases that have been predicted to be present have not been detected during the test

- Two gases, 1,2-dichloroethane and 2-ethoxyethanol, have been detected without being predicted

- All the detected concentrations are lower than predicted, exception made for ammonia (factor of 10)

From table 8 the following can be remarked:

- Times to SMAC derived from test results are always greater than predicted, except for 1,2-dichloroethane and ammonia

- For 2-propanol the prediction was $\mathbf{1 3}$ days, that did not comply with the projected duration of isolated phase; Test results show a time to SMAC five orders of magnitude greater. Also for Xylenes test results show a Time to SMAC four orders of magnitude greater than predicted

- According to test results, time to SMAC for all gases is always greater than the projected duration of 180 days, while according to predictions, five gases did not comply with the projected duration

\begin{tabular}{|c|c|c|c|}
\hline & Concentration to $S$ & C (180 d) ratio [- & \\
\hline Trace gas & $\begin{array}{c}\text { Final Offgassing } \\
\text { Evaluation }(\mathrm{A})\end{array}$ & $\begin{array}{l}\text { Design Phase } \\
\text { Predictions (B) }\end{array}$ & Ratio A/B \\
\hline Acrolein & $3.06 \mathrm{E}-04$ & $3.80 \mathrm{E}-04$ & 0.80 \\
\hline Carbon monoxide & $1.18 \mathrm{E}-04$ & $2.63 E-03$ & 0.04 \\
\hline Ammonia & $6.26 \mathrm{E}-05$ & $6.18 \mathrm{E}-06$ & 10.13 \\
\hline 1,2-Dichloroethane & $4.80 E-05$ & $0.00 \mathrm{E}+00$ & inf. \\
\hline Methanol & $2.44 \mathrm{E}-05$ & $1.37 \mathrm{E}-03$ & 0.02 \\
\hline Acetaldehyde & $1.82 \mathrm{E}-05$ & $3.41 \mathrm{E}-04$ & 0.05 \\
\hline 2-Ethoxyethanol & $9.29 \mathrm{E}-06$ & $0.00 E+\infty$ & inf. \\
\hline Methyl ethyl ketone & $2.80 E-06$ & $1.71 \mathrm{E}-04$ & 0.02 \\
\hline Toluene & $1.27 E-06$ & $3.13 \mathrm{E}-04$ & 0.00 \\
\hline Dichloromethane & $4.60 E-07$ & $8.53 E-05$ & 0.01 \\
\hline Methane & $1.83 \mathrm{E}-07$ & $1.62 \mathrm{E}-06$ & 0.11 \\
\hline Octamethyltrisiloxane & 5.02E-08 & $4.72 \mathrm{E}-08$ & 1.06 \\
\hline 2-Propanol & 1.12E-08 & $6.60 \mathrm{E}-03$ & 0.00 \\
\hline Xylene (sum) & $5.40 \mathrm{E}-10$ & $5.94 \mathrm{E}-06$ & 0.00 \\
\hline Formaldehyde & $0.00 \mathrm{E}+00$ & $2.60 \mathrm{E}-02$ & 0.00 \\
\hline Carbon dioxide & $0.00 \mathrm{E}+00$ & $4.25 \mathrm{E}-08$ & 0.00 \\
\hline Hydrogen & $0.00 \mathrm{E}+00$ & $0.00 E+00$ & - \\
\hline Mercury & $0.00 \mathrm{E}+00$ & $0.00 \mathrm{E}+00$ & - \\
\hline Freon 113 & $0.00 \mathrm{E}+00$ & $2.56 \mathrm{E}-05$ & 0.00 \\
\hline Indole & $0.00 \mathrm{E}+00$ & $0.00 E+\infty$ & - \\
\hline Trichloroethylene & $0.00 E+00$ & $2.18 \mathrm{E}-04$ & 0.00 \\
\hline Trimethylsilanol & $0.00 E+00$ & $6.47 \mathrm{E}-04$ & 0.00 \\
\hline Hydrazine & $0.00 \mathrm{E}+00$ & $0.00 E+00$ & - \\
\hline Methylhydrazine & $0.00 \mathrm{E}+00$ & $0.00 E+00$ & \\
\hline
\end{tabular}

Table 7 - On station nominal conditions, comparison between predictions and test results

\begin{tabular}{|c|c|c|c|}
\hline & \multicolumn{2}{|c|}{ Time to SMAC $(1 \mathrm{~h})[\mathrm{d}]$} & \\
\hline Trace gas & $\begin{array}{l}\text { Final Offgassing } \\
\text { Evaluation (A) }\end{array}$ & $\begin{array}{l}\text { Design Phase } \\
\text { Predictions (B) }\end{array}$ & Ratio A/B \\
\hline Acrolein & 285.7 & 223.9 & 1.28 \\
\hline 1,2-Dichloroethane & $\overline{545.1}$ & 4367.3 & 0.12 \\
\hline Ammonia & 598.0 & 5260.5 & 0.11 \\
\hline Carbon monoxide & 667.5 & 29.7 & 22.47 \\
\hline Methanol & 2389.4 & 42.2 & 56.64 \\
\hline Acetaldehyde & 3596.7 & 191.3 & 18.81 \\
\hline Toluene & 10299.4 & 41.5 & 248.10 \\
\hline Methyl ethyl ketone & 23390.8 & 352.1 & 66.43 \\
\hline Methane & 71482.3 & 8013.4 & 8.92 \\
\hline 2-Ethoxyethanol & 188019.1 & 11248.9 & 16.71 \\
\hline Dichloromethane & 997058.6 & 4494.4 & 221.85 \\
\hline 2-Propanol & 7814044.9 & 13.3 & 588628.61 \\
\hline Octamethyttrisiloxane & 26110683.5 & 2872550.3 & 9.09 \\
\hline Xylene (sum) & 47387271.1 & 3540.4 & 13384.82 \\
\hline Carbon dioxide & inf. & 545259.4 & inf. \\
\hline Formaldehyde & inf. & 5.1 & inf. \\
\hline Trimethylsilanol & inf. & 303.8 & inf. \\
\hline Trichloroethylene & inf. & 1617.8 & inf. \\
\hline Freon 113 & inf. & 446.6 & inf. \\
\hline Hydrogen & inf. & 9723314.3 & inf. \\
\hline Mercury & inf. & inf. & - \\
\hline Indole & inf. & inf. & $\overline{-}$ \\
\hline Hydrazine & inf. & inf. & - \\
\hline Methylhydrazine & inf. & int. & - \\
\hline
\end{tabular}

Table 8 - Isolated conditions, comparison between predictions and test results

\section{COMPARISON TO OTHER ISS ELEMENT TESTS}

Offgassing tests conducted for the U.S. Segment elements have been in the passive mode. That is, the module systems were not powered during the testing. Testing duration ranged from 120 hours for Node 1 to 444 hours for the U.S. Lab module. The typical goal is for 
the minimum passive testing duration to be approximately one-fifth the planned elapsed time between final hatch closure on the ground and first crew entry on orbit. This allows for the passive offgassing test results to prove more precise prediction of cabin air quality at the time the crew enters the module for the first time. In the next planned Columbus offgassing test, the module will be passive and with payloads integrated. The test duration will be set according to the above mentioned guideline to ensure consistency. Table 9 provides a summary of the major U.S. Segment passive element-level offgassing test results.[6, 7,8$]$

\begin{tabular}{|l|r|r|r|}
\hline \multirow{2}{*}{ TRACE GAS } & \multicolumn{3}{|c|}{ GENERATION RATE (mg/h) } \\
\cline { 2 - 4 } & U.S. LAB & NODE 1 & AIRLOCK \\
\hline Methanol & 1.07 & 0.0396 & 0.0757 \\
\hline Ethanol & 1.06 & 0.8873 & 0.266 \\
\hline 2-propanol & 1.08 & 0.8276 & 0.237 \\
\hline n-propanol & 0.15 & 0.1377 & 0.0669 \\
\hline 2-methyl-2-propanol & 0 & 0.0211 & 0 \\
\hline n-butanol & 0.097 & 0.1099 & 0.0298 \\
\hline Ethanal & 0.04 & 0.0366 & 0.00298 \\
\hline 2-propenal & 0 & 0.0001 & 0 \\
\hline Propanal & 0 & 0.0278 & 0.0122 \\
\hline 2-methyl-2-propenal & 0 & 0.0211 & 0 \\
\hline Butanal & 0 & 0.2095 & 0 \\
\hline Pentanal & 0 & 0.0079 & 0 \\
\hline Hexanal & 0 & 0.0079 & 0 \\
\hline Heptanal & 0 & 0.0079 & 0 \\
\hline Methylbenzene & 0.076 & 0.0612 & 0.0238 \\
\hline 1,2-\& 1,3-dimethylbenzenes & 0 & 0.0553 & 0 \\
\hline 1,4-dimethylbenzene & 0 & 0.0211 & 0 \\
\hline Ethylbenzene & 0 & 0.0211 & 0 \\
\hline Butyl acetate & 0 & 0.0079 & 0 \\
\hline Dichloromethane & 0.035 & 0.1163 & 0 \\
\hline Tetrachloroethene & 0.038 & 0 & 0 \\
\hline Trichlorofluoromethane & 0 & 0.0211 & 0 \\
\hline Trichlorotrifluoroethane & 0.5 & 0.0702 & 0.0147 \\
\hline 2-propanone & 0.42 & 0.2178 & 0.0499 \\
\hline 2-butanone & 0.14 & 0.1101 & 0.016 \\
\hline Cyclohexanone & 0.03 & 0.0367 & 0.0189 \\
\hline Hexamethydcyclotrisiloxane & 0.69 & 0.0211 & 0.208 \\
\hline Octamethylcyclotetrasiloxane & 0.22 & 0.15 & 0.0258 \\
\hline Decamethylcyctopentasiloxane & 0.07 & 0 & 0 \\
\hline Trimethylsilanol & 0.93 & 0 & 0.149 \\
\hline Carbon Monoxide & 0.01 & 0 & 0 \\
\hline 1,2-dichloroethane & & 0 & 0 \\
\hline
\end{tabular}

Table 9 - Results from ISS U.S. Segment Passive Offgassing Tests

In comparison, results from the Columbus module active testing indicates offgassing rates that are comparable to those observed during passive testing of other U.S. Segment modules. Overall, the Columbus module testing results most closely resembles those obtained during testing of Node 1.

These are very encouraging results because temperature and equipment age can significantly affect offgassing rate. The active testing condition can induce elevated temperature that can contribute up to 10 times greater offgassing rates compared to equipment at 20 ${ }^{\circ} \mathrm{C}$.[9] Equipment age can also result in significant offgassing rate reduction. The offgassing rate for equipment aged 50 days has been reported to decrease by $>90 \%$.[10] Taking these effects into account, the Columbus module equipment offgassing load can be expected to be lower when launched and activated on. orbit. A more direct comparison will be possible once the' final passive offgassing test is conducted on the Columbus module.

\section{CONCLUSION}

Conclusions from the Columbus module active offgassing test are the following:

1. The offgassing load from the Columbus module is expected to be well within the capabilities of the ISS's active cabin air quality control equipment.

2. Columbus module active offgassing test results are comparable to those observed from passive tests of other U.S. Segment modules, particularly Node 1.

3. Conducting the final passive offgassing test as close to the Columbus module's launch is necessary to most accurately predict the trace gas concentrations at the time the crew enters for the first time.

\section{ACKNOWLEDGMENTS}

Chemical analyses have been performed by Dr. Christian Zorn and Thomas Fangmeyer, Bremer Umweltilnstitut, and by Dr. Joachim Kosack, EADS Space Transportation.

We gratefully acknowledge Dr. Thomas Rohr, European Space Agency, for the support provided in defining the offgassing test conditions.

\section{REFERENCES}

1. COL-ESA-RQ-001, Columbus System Requirements Document (CSRD)

2. ESA-PSS-03-401, Atmosphere Quality Standards in Manned Space Vehicles

3. SAE paper 891513, Leban, M. I., Wagner, P. A., Space Station Freedom gaseous trace contaminant load model development

4. H-EV-1-12-CNES, Physiological Environment Human Factors Limitations

5. SSP 41000b, International Space Station Alpha System Specification

6. NASA ED62(134-98) Perry, J.L., International Space Station Node 1 Trace Contaminant Control Capability Assessment. November 2, 1998

7. NASA FD21(01-021) Perry, J.L., International Space Station Mission 5A Trace Contaminant Control Capability Assessment

8. NASA FD21(01-085) Perry, J.L., International Space Station Mission 7A Trace Contaminant Control Capability Assessment

9. Perry, J.L.: Trace Chemical Contaminant Generation Rates for Spacecraft Contamination Control System Design. NASA TM-108497. NASA MSFC, August 1995, p. 5

10. Olcott, T.M.: Development of a Sorber Trace Contaminant Control System Including Pre- and 
Post-Sorbers for a Catalytic Oxidizer. NASA CR2027. NASA: May 1972, pp. 9-10

\section{CONTACT}

For more information, please contact

Riccardo Rampini, Functional Architecture and Environment

Alenia Spazio S.p.A.

Strada Antica di Collegno 253 - 10146 Torino phone: +39 0117180758

email: riccardo.rampini@aleniaspazio.it

\section{DEFINITIONS, ACRONYMS, ABBREVIATIONS}

ATCS: Active Thermal Control System

CCN: Contract Change Notice

CSRD: Columbus System Requirements Document

DAD: Diode Array Detection

DMS: Data Management System

DNPH: Dinitrophenylhydrazine

ECLSS: Environmental Control and Life Support System

EDPS: Electrical Power Distribution System

ESA: European Space Agency

FID: Flame Ionization Detector

GC: Gas Chromatography

HPLC: High Performance Liquid Chromatography

IMV: Inter Module Ventilation

ISS: International Space Station

MS: Mass Spectrometry

MST: Mission Simulation Test

NASA: National Aeronautics and Space Administration

PBA: Portable Breathing Apparatus

PFEX: Portable Fire Extinguisher

PCMCIA: Personal Computer Memory Card International Association

SAC: Starboard Cone Aft Panel

SMAC: Spacecraft Maximum Allowable Concentration

TO: Total Organics 